\title{
Strengthening via Microstructure Refinement in Bulk Al-4 mass\% Fe Alloy Using High-Pressure Torsion
}

\author{
Jorge M. Cubero-Sesin ${ }^{1,2, *}$ and Zenji Horita ${ }^{1,2}$ \\ ${ }^{1}$ Department of Materials Science and Engineering, Faculty of Engineering, Kyushu University, Fukuoka 819-0395, Japan \\ ${ }^{2}$ International Institute for Carbon-Neutral Energy Research (I²CNER), Kyushu University, Fukuoka 819-0395, Japan
}

A bulk $\mathrm{Al}-4$ mass $\%$ Fe alloy processed by extrusion or by a combination of extrusion and successive annealing was subjected to severe plastic deformation (SPD) through high-pressure torsion (HPT) for up to 75 revolutions. Microstructural evolution was examined by optical microscopy and transmission electron microscopy with special attention for the grain refinement in the Al matrix and for the distribution and morphology of Fe-containing intermetallic particles. Solubility of $\mathrm{Fe}$ in the Al matrix was studied by X-ray diffraction (XRD). A significant increase in Vickers microhardness was observed because of the development of an ultrafine-grained matrix and a fine fragmentation of the intermetallic particles especially at an early stage of SPD. The strengthening was affected by the initial state of the microstructure prior to HPT, but finally it was saturated at a higher degree of straining. [doi:10.2320/matertrans.MD201127]

(Received August 8, 2011; Accepted September 5, 2011; Published October 19, 2011)

Keywords: aluminum-iron alloys, high strength, microstructure evolution, ultrafine grains, intermetallic phases, high-pressure torsion

\section{Introduction}

Due to its negligible solid solubility at room temperature, the use of $\mathrm{Fe}$ as an alloying element in $\mathrm{Al}$ has been limited because it forms brittle intermetallics. ${ }^{1-5)}$ However their often complex crystalline structures give them unique properties such as high strength even at higher temperatures. ${ }^{6,7)}$ Therefore, there can be good potential to increase the strength of Al-Fe alloys without greatly compromising ductility if the Fe-containing intermetallics are present in finely dispersed states. It is also possible to improve other properties such as temperature and corrosion resistance with a fine dispersion of the Fe-bearing intermetallics. The Al-rich region in the $\mathrm{Al}-\mathrm{Fe}$ binary system has a eutectic reaction at $\sim 1.8$ mass $\%$ Fe between primary $\alpha$-Al and the $\mathrm{Al}_{3} \mathrm{Fe}$ intermetallic compound. Cast alloys with $\mathrm{Fe}$ concentrations above this eutectic value often exhibit unfavorable coarse phases of these intermetallic compounds. ${ }^{1-5)}$ Intermetallics in the form of fine structures help to stabilize the Al matrix and inhibit the movement of dislocations. The presence of $\mathrm{Fe}$ could then increase hardness levels at the steady state attained during severe plastic deformation (SPD) of pure $\mathrm{Al}$ and some Al alloys. ${ }^{8-12)}$ Therefore, in recent years, research of different techniques has been attempted to refine secondary phases. Cast Al-Fe alloys have been studied to some extent by SPD through high-pressure torsion (HPT) and equal-channel angular pressing (ECAP), ${ }^{13-15)}$ especially emphasizing the role of supersaturation of $\mathrm{Fe}$ and dispersion of intermetallic phases. The study by Senkov et al. ${ }^{13)}$ applied HPT to a cast Al-11 mass\% Fe alloy and reported the formation of a nanocrystalline structure in the Al matrix and dispersion of intermetallics with $<\sim 1 \mu \mathrm{m}$ in size. Supersaturation of $\mathrm{Fe}$ was attained by HPT and increased strengthening was achieved by a subsequent aging treatment. The report by Stolyarov et al. ${ }^{15)}$ presented the results from an $\mathrm{Al}$ 5 mass $\% \mathrm{Fe}$ alloy processed by ECAP including the formation of an ultrafine-grained structure. The importance of backpressure to facilitate the fragmentation of intermetal-

*Graduate Student, Kyushu University lics and to improve ductility was also mentioned. Some other studies have applied HPT to Al-Fe alloys prepared by mechanical alloying (MA) or rapid quenching (RQ) ${ }^{16-18)}$ and highlighted the use of HPT to refine and dissolve different stable and metastable intermetallic phases. However, there have been no systematic studies concerning the evolution of microstructures and mechanical properties with intense straining by HPT. Special attention is paid for the refinement of the coarse intermetallics by HPT in the $\mathrm{Al}-4 \% \mathrm{Fe}$ alloy having different forms of microstructures after extrusion and annealing and the subsequent effect on the mechanical properties.

\section{Experimental Materials and Procedures}

The bulk material used in this study was provided by Kobe Steel, Ltd. in the form of an extruded rod with $20 \mathrm{~mm}$ in diameter. This rod was obtained from an $\mathrm{Al}$ cast ingot with dimensions of $155 \mathrm{~mm}$ in diameter and $200 \mathrm{~mm}$ in length. The extrusion was carried out at a temperature of $723 \mathrm{~K}$ and a speed of $2 \mathrm{~mm} / \mathrm{min}$. The Fe content of the alloy was prepared to have an $\mathrm{Fe}$ weight fraction of $4 \%$ and verified after casting to be $3.72 \mathrm{mass} \%$ by inductively coupled plasma atomic emission spectroscopy (ICP-AES). Hence, the composition of the alloy is referred to its nominal fraction of $4 \% \mathrm{Fe}$. The presence of other impurities was estimated to be low enough to be considered in this study. The microstructure of the cast material was observed with a Hitachi S-4300SE scanning electron microscope (SEM) operating at $20 \mathrm{kV}$. Figure 1 shows a micrograph of the typical microstructure of the Al$4 \%$ Fe cast alloy. The formation of the coarse intermetallic phase is shown clearly in bright contrast and the presence of the primary $\alpha$-Al phase can also be appreciated from the micrograph. Besides the coarse intermetallic phase, it appears that a fine eutectic phase exists surrounding the $\alpha$-phase dendrites. As mentioned before, this eutectic is composed of $\alpha-\mathrm{Al}$ and the $\mathrm{Al}_{3} \mathrm{Fe}$ intermetallic compound. The coarse intermetallic phase is probably composed of the $\mathrm{Al}_{3} \mathrm{Fe}$ type, but others such as $\mathrm{Al}_{5} \mathrm{Fe}_{2}$, and even metastable $\mathrm{Al}_{6} \mathrm{Fe}$ could be present according to the effective cooling rates as a 


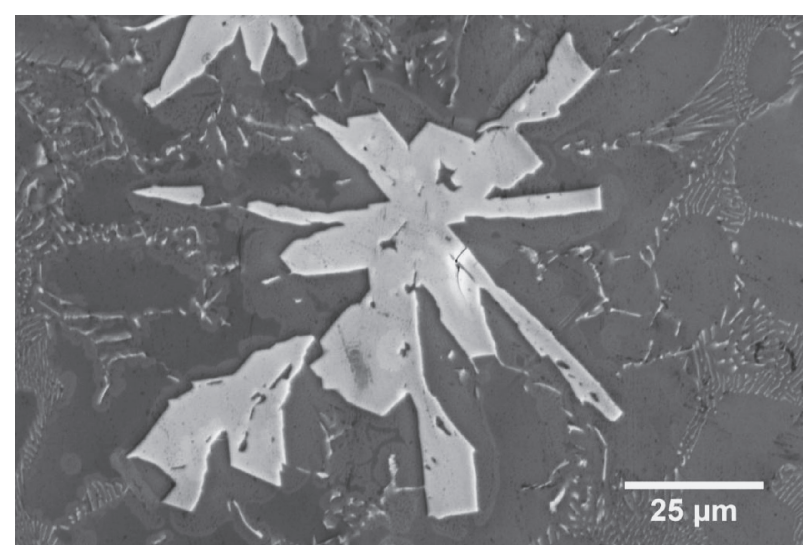

Fig. 1 SEM micrograph of $\mathrm{Al}-4 \%$ Fe as-cast alloy.

result of the casting process. ${ }^{1-5)}$ A precise identification of intermetallic phases present in this alloy will be reported elsewhere.

For HPT processing, the extruded rods were cut using an abrasive wheel into disks with $0.9 \mathrm{~mm}$ thicknesses and then $10 \mathrm{~mm}$ diameter disks were extracted using an electrical wirecutter. The HPT facility consists of an upper anvil and a lower anvil that rotate with respect to each other under an applied load. ${ }^{19)}$ Both anvils contain matching shallow grooves $10 \mathrm{~mm}$ in diameter and $0.25 \mathrm{~mm}$ in depth. The $10 \mathrm{~mm}$ disks are placed directly over the groove in the lower anvil, which is then raised to meet the upper anvil until a high compressive load is applied. The disks are then enclosed between the matching grooves of the anvils, after a portion of material flows out of the edges during pressing. HPT was conducted at room temperature by rotating the lower anvil at $1 \mathrm{rev} / \mathrm{min}$ with respect to the upper anvil under a pressure of $6 \mathrm{GPa}$. Different disks were processed for $N=1,5,10,20$, 50 and 75 revolutions. The final thickness of the samples after processing is $0.6 \pm 0.1 \mathrm{~mm}$. A group of disks was processed in an as-extruded condition (EXT+HPT), whereas another group was annealed after the extrusion in air at $773 \mathrm{~K}$ for $1 \mathrm{~h}$ and left to cool inside the furnace prior to HPT operation $(\mathrm{EXT}+\mathrm{ANN}+\mathrm{HPT})$.

Mechanical properties of the HPT-processed disks were evaluated in terms of Vickers microhardness $\left(\mathrm{H}_{\mathrm{V}}\right)$ using an Akashi MVK-E3 tester by applying a load of $50 \mathrm{~g}$ for a duration of $15 \mathrm{~s}$. Surface preparation for hardness testing was done first by polishing using papers with 320, 1000 and 2000 grits and then buffed with an alumina powder solution to obtain a mirror-like surface. The measurements were made along $30^{\circ}$-spaced radial directions in the surface of the disks, for a total of 12 radii. The first indentation was done at $0.1 \mathrm{~mm}$ from center and the following by every $0.5 \mathrm{~mm}$ up to $4.5 \mathrm{~mm}$, for a total of 120 indentations. Measurements were averaged at equal distances from the center. The evolution of microhardness with the strain introduced by torsion was examined by the use of the following relation between the equivalent strain $\varepsilon$ and the distance from the disk center $r$ in HPT: ${ }^{19)}$

$$
\varepsilon=\frac{2 \pi r N}{\sqrt{3} t}
$$

where $N$ corresponds to the number of revolutions and $t$ is the sample thickness.

The observation of the initial states as well as the resulting microstructures of the HPT-processed disks was performed both by optical microscopy (OM); to study the size and morphology of the coarse intermetallic phase, and by transmission electron microscopy (TEM); to observe the fine intermetallic particles and the degree of grain refinement in the Al matrix.

In preparation for OM, the same surfaces used for the microhardness measurements were then electro-polished using a solution of $20 \% \mathrm{H}_{2} \mathrm{SO}_{4}+80 \% \mathrm{CH}_{3} \mathrm{OH}$ and then electro-etched using a solution of $5 \% \mathrm{HF}+95 \% \mathrm{H}_{2} \mathrm{O}$. OM observations were performed using a Nikon LV150 optical microscope equipped with a digital image capture system. To measure the intermetallic particles in the samples after HPT, several micrographs were recorded at a lower magnification at different distances from the center of the disks, ensuring that an entire area of each disk was covered. The size of each particle was calculated by fitting an ellipse and averaging the major and minor axes, which were measured manually. The state of the intermetallic particles prior to HPT was measured in a similar way from representative micrographs, and computed by recognition of dark contrast using an image recognition software. The aspect ratio of the particles was also computed as the ratio of the major to the minor axis.

For TEM samples, disks with $3 \mathrm{~mm}$ in diameter were punched out from the outer region of HPT disks at $\sim 3 \mathrm{~mm}$ from the center, ground with polishing papers to a thickness of $0.15 \mathrm{~mm}$ and further thinned using the solution of $20 \%$ $\mathrm{H}_{2} \mathrm{SO}_{4}$ and $80 \% \mathrm{CH}_{3} \mathrm{OH}$ in a twin-jet electro-polishing apparatus. TEM was undertaken using a Hitachi H8100 microscope operating at $200 \mathrm{kV}$. Selected area electron diffraction (SAED) patterns were obtained from areas covering $\sim 6.3 \mu \mathrm{m}$ in diameter.

To study the solid solubility of $\mathrm{Fe}$ in the $\mathrm{Al}$ matrix, additional $3 \mathrm{~mm}$ disks were extracted in a way similar to the preparation of TEM samples and were processed in a Rigaku $\mathrm{X}$-ray diffractometer with the $\mathrm{Cu}$-target $\mathrm{K} \alpha$ radiation. $\mathrm{LaB}_{6}$ powder was used simultaneously with the samples for $2 \theta$ offset correction. The lattice constant of each of the HPT processed samples was determined with the Nelson-Riley extrapolation method using the Al fundamental reflections (111), (200), (220) and (311). The amount of Fe in solid solution was estimated from its linear relationship with the lattice constant as described by Jones. ${ }^{20)}$

\section{Results and Discussion}

Figure 2 shows the microstructure observations in the EXT and EXT+ANN states prior to HPT. Figures 2(a) and 2(b) correspond to low magnification optical micrographs taken from the $\mathrm{Al}-4 \% \mathrm{Fe}$ disks. In both cases the coarse intermetallic phase is visible in darker contrast embedded in the Al matrix. However, difference in the morphology of the intermetallics is apparent. In the case of Fig. 2(a), most of the particles resemble the original shapes from the as-cast material (such as the large particle observed in Fig. 1) and the volume fraction of the particles is estimated to be $\sim 4.1$ vol\%. In Fig. 2(b), thin and needle-like shapes appear 


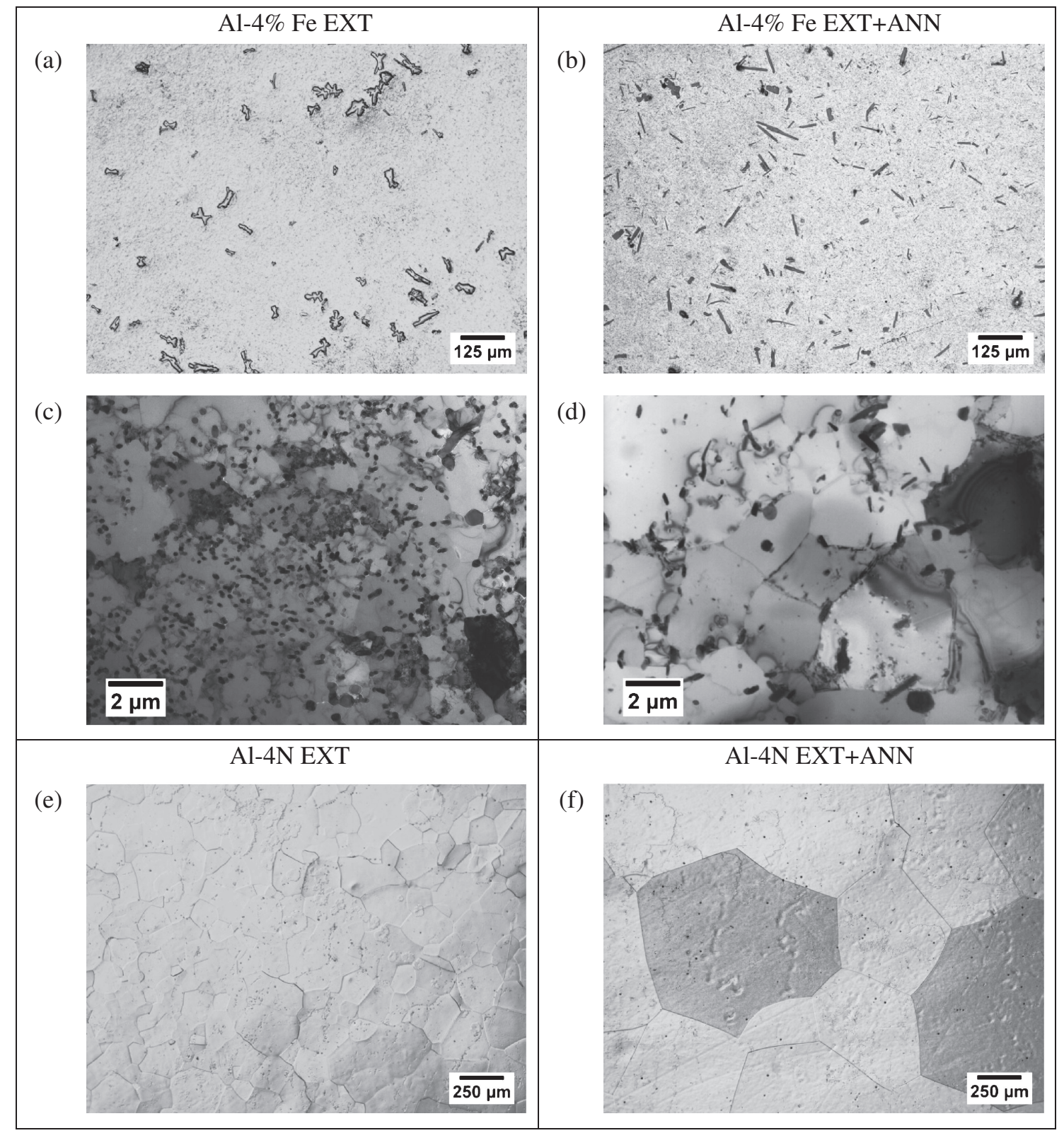

Fig. 2 Micrographs of $\mathrm{Al}-4 \% \mathrm{Fe}$ and pure $\mathrm{Al}(99.99 \%)$ in as-extruded state and after annealing.

to have grown as a result of the annealing. However, in this case the volume fraction of the particles is only of $\sim 2.2 \%$. A large variation in the sizes and shapes of the particles was observed throughout the surfaces of the disks. The size of particles in Fig. 2(a) was estimated to be $d_{\mathrm{p}}=38 \pm 18 \mu \mathrm{m}$ with an aspect ratio of $\sim 2$, whereas the size of particles in Fig. 2(b) was $d_{\mathrm{p}}=25 \pm 12 \mu \mathrm{m}$ with an aspect ratio of $\sim 4$.

In order to observe the degree of grain refinement in the Al-matrix, TEM samples were prepared from both EXT and EXT+ANN states. Figures 2(c) and 2(d) are the corresponding bright field micrographs of representative regions. At this magnification, both the fine intermetallics in eutectic nature and the matrix grain structure are visible. The intermetallic particles were mostly spherical, as shown in Fig. 2(c), with a size of $d_{\mathrm{p}}=0.18 \pm 0.05 \mu \mathrm{m}$ in contrast with Fig. 2(d) where the size increased to $d_{\mathrm{p}}=0.29 \pm 0.13 \mu \mathrm{m}$ and some particles grew to ellipsoidal shapes. It seems that at this level the annealing favored the coalescence as well as growth of smaller globular particles. Inspection of Figs. 2(c) and 2(d) show that the average grain size for the as-extruded state is of $d=1.4 \pm 0.2 \mu \mathrm{m}$ whereas that of the annealed state is of $d=2.8 \pm 0.3 \mu \mathrm{m}$; thus the extruded state is about half the size of the annealed state.

To understand the effect of the presence of $\mathrm{Fe}$ and the extent of the annealing, a sample from an extruded rod of pure Al was observed by optical microscopy and then annealed under the same conditions as the $\mathrm{Al}-4 \% \mathrm{Fe}$ alloy. Figures 2(e) and 2(f) show the corresponding micrographs. The average grain size from the extruded material in Fig. 2(e) is $d \approx 150 \mu \mathrm{m}$, and by annealing it grew almost by a factor of 4 to $d \approx 550 \mu \mathrm{m}$ as shown in Fig. 2(f). It is suggested then that the intermetallic particles greatly assist the refinement of the Al matrix and restrict the grain growth during annealing.

Figure 3 presents optical micrographs taken near the periphery of the HPT-processed disks for $N=1,10$ and 50 in order to show the effect of HPT on the coarse intermetallic 


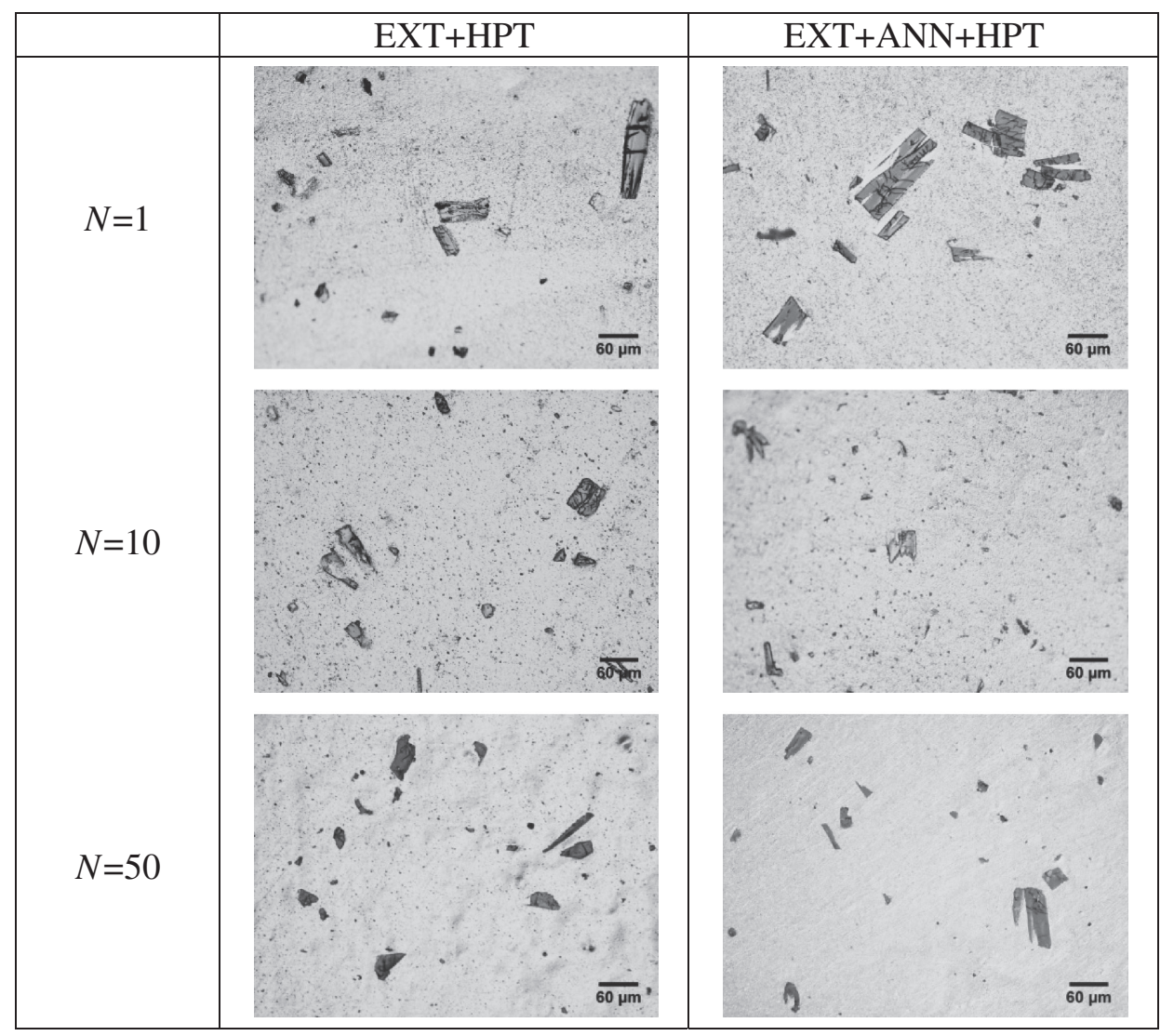

Fig. 3 Optical micrographs of coarse second phase particles at periphery of Al-4\% Fe EXT+HPT (left) and EXT+ANN+HPT (right) disks.

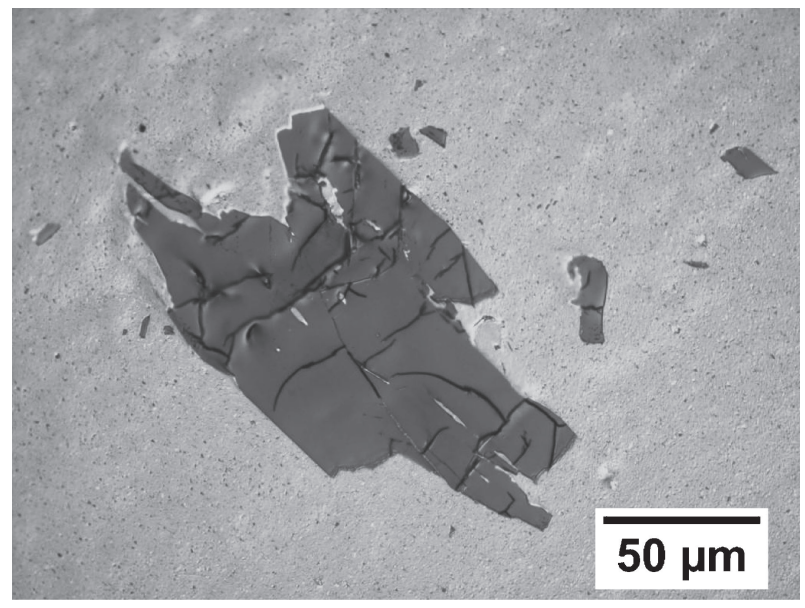

Fig. 4 Optical micrograph of $\mathrm{Al}-4 \% \mathrm{Fe}$ EXT+ANN+HPT sample processed for $N=75$ revolutions.

particles. It is observed that the particles were both deformed and fragmented, being exemplified in ways such as visible fracture lines, bending and collision. Thus, it is said that strong shear was exerted on such hard particles through HPT. The random nature in the size and complex morphology of these particles after shearing is also clear from the micrographs. Figure 4 shows a magnified view of an intermetallic phase observed in the samples after 75 revolutions. The dark contrast lines extending across the particle clearly show how the imposed strain was introduced. Perhaps due to the shape of this type of particle, further fragmentation was not possible in contrast with other, more elongated ones. Nonetheless it is possible to distinguish numerous separated fragments of different sizes.

Figure 5 shows a succession of histograms to show the distribution of the measured sizes from $\mathrm{OM}$, as a result of the application of HPT. More than 200 particles were measured in every disk, both in the EXT and EXT+ANN cases. It is shown that despite larger particles are still present at higher numbers of revolutions, more than $90 \%$ of particles are reduced to the sizes below $d_{\mathrm{p}}=40 \mu \mathrm{m}$, with no significant difference among extruded and annealed samples. It should be noted that the measurement of particle size was feasible with the maximum resolution of $\sim 2 \mu \mathrm{m}$ attained in this study by $\mathrm{OM}$.

The average size from the measurements of the intermetallic particles by OM is shown in Fig. 6 as a function of the number of revolutions. As described earlier in Figs. 2(a) and 2(b), variation is large and no significant differentiation was made among EXT and EXT+ANN samples. The average size computed from the analysis of the as-cast state was $d_{\mathrm{p}}=36 \pm 27 \mu \mathrm{m}$, which was drawn in Fig. 6 as a dotted line for reference. The average size of the as-cast particles is similar to the result from the as-extruded case, which is consistent with the affirmation made about the similar morphology of particles in Fig. 2(a) with the as-cast particles, such as the one presented in Fig. 1. The larger standard deviation in the as-cast state is attributed to a few very long particles, most likely fragmented after extrusion. As a 

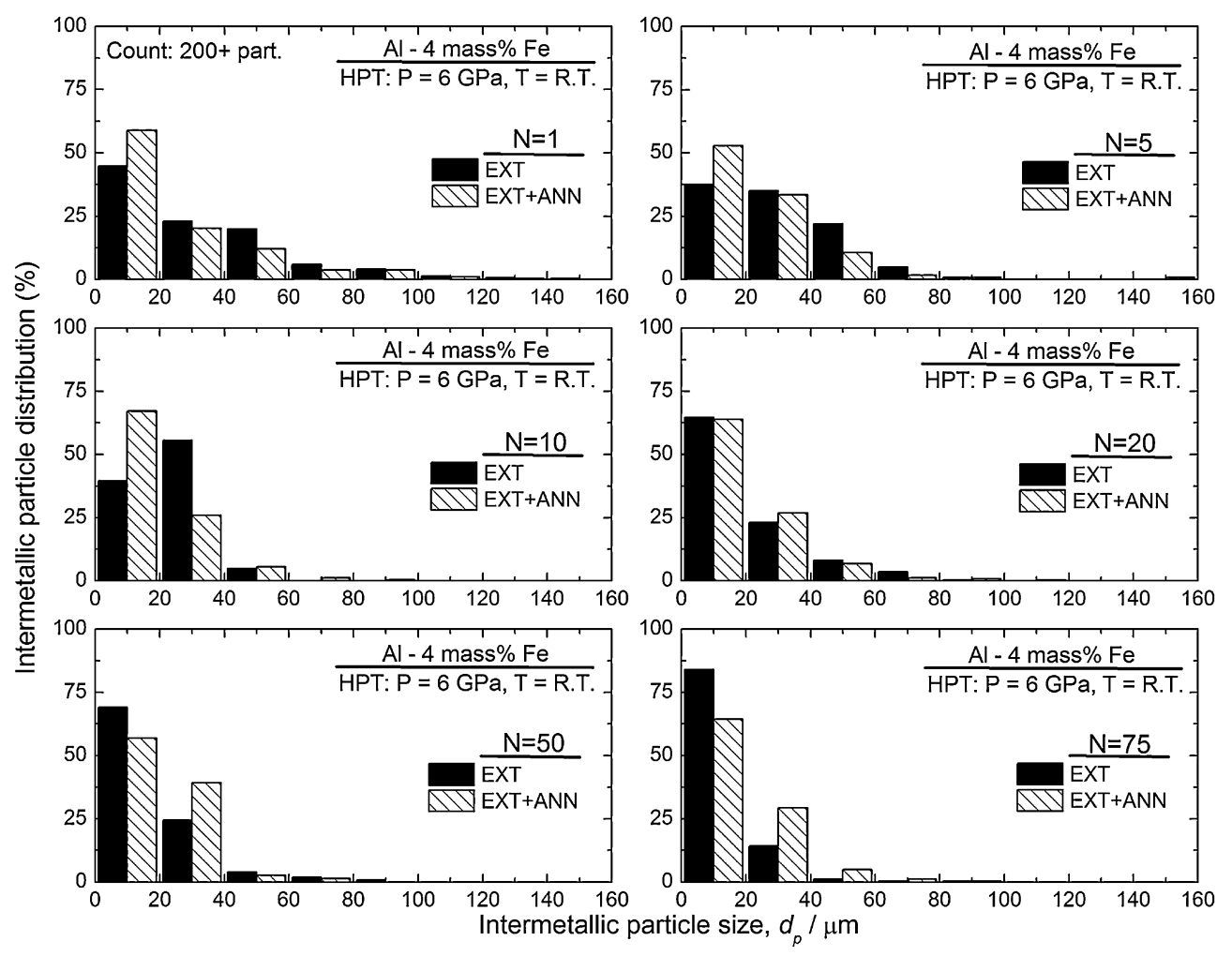

Fig. 5 Distribution of intermetallic particle sizes in EXT and EXT+ANN disks processed by HPT.

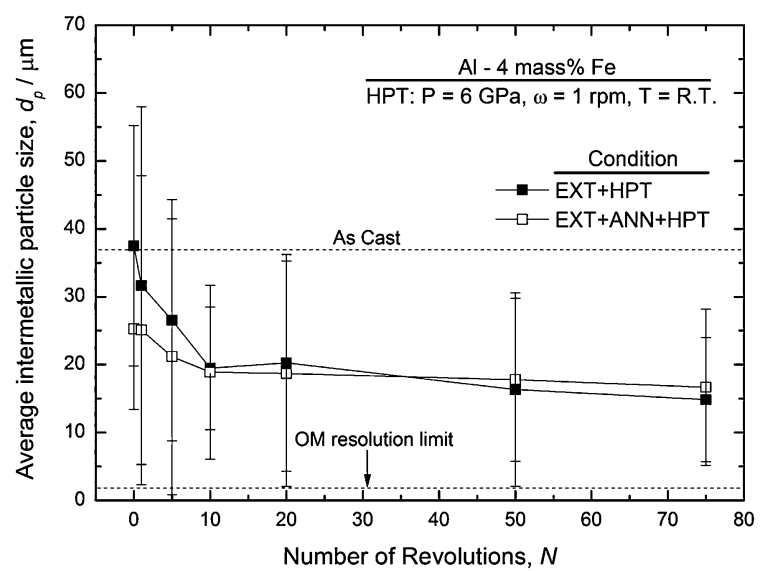

Fig. 6 Average intermetallic particle size against number of revolutions for EXT and EXT+ANN samples processed by HPT.

consequence of this, the aspect ratio of the as-cast state is also slightly larger $(\sim 2.5)$ compared with the as-extruded case $(\sim 2)$. From the trend observed in Fig. 6, it can be concluded that there is a gradual reduction in the average size and standard deviation of the large intermetallics as a result of the application of HPT, especially at higher levels of imposed strain. As mentioned earlier in association with Fig. 5, despite a few resilient particles such as the one shown in Fig. 4 after 75 revolutions, the fraction of smaller particles is increased and thus the standard deviation is reduced. No major difference can be appreciated between extruded and annealed samples. The resolution limit of the optical microscope $(\sim 2 \mu \mathrm{m})$, as stated earlier, is also shown in Fig. 6. It is reasonable to suggest that existing particles and fragments below the size of $2 \mu \mathrm{m}$ are generated and further refined. Thus, the decreasing trend depicted in Fig. 6 would be more prominent if smaller fragments were to be considered.

To support the last statement, Fig. 7 shows micrographs of two examples of smaller intermetallic particles observed by TEM. In the case of Fig. 7(a), a particle with a size of $d_{\mathrm{p}} \sim 2.7 \mu \mathrm{m}$, presumably existing from the as-cast state, due to its regular shape and smooth edges, was observed in an $\mathrm{EXT}+\mathrm{ANN}+\mathrm{HPT}$ sample after processing for 10 revolutions. A darker contrast zone resembling fracture at the center of the particle can be appreciated from the bright field image. As a result of this, the dark field image obtained from the selected beam indicated by the arrow in the inset shows a bright contrast in the form of fracture zone at the center of the particle. Some dislocations are visible in the lower right section of the particle and this suggests how this intermetallic particle is sheared in obstructing the deformation in the matrix and the subsequent strengthening of this alloy. It is noted that some refined grains in the Al matrix are visible in brighter contrasts because of diffracted beams which may be included in the aperture when recording the dark field image. Figure 7(b) depicts another intermetallic particle, with a size of $d_{\mathrm{p}} \sim 2.5 \mu \mathrm{m}$, obtained from an extruded sample after HPT processing for 75 revolutions. In this case, due to an irregular shape, this can be a possible fragment which contains large strain as evident from a clear bend contour visible in bright and dark field images. The dark field image obtained from the selected beam in the SAED pattern also reveals the presence of some dislocations within the particle.

The refinement in the Al matrix was already shown in the previous discussion from the dark field image in Fig. 7(a). The evolution of the microstructure with straining by HPT for the EXT+HPT samples was examined through the analysis 
(a)

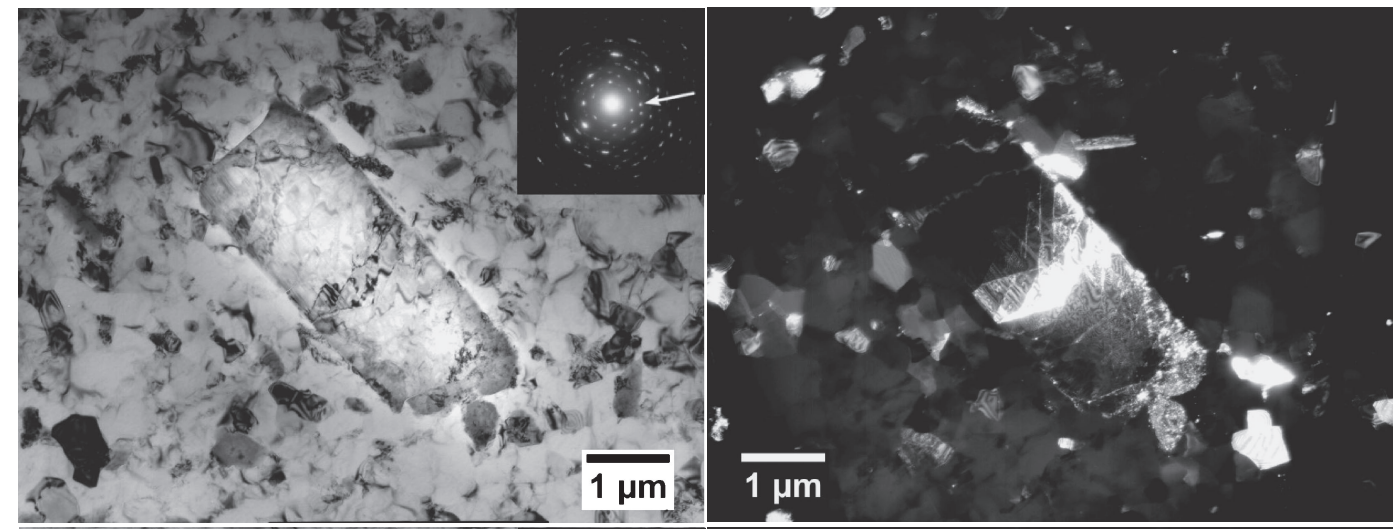

(b)

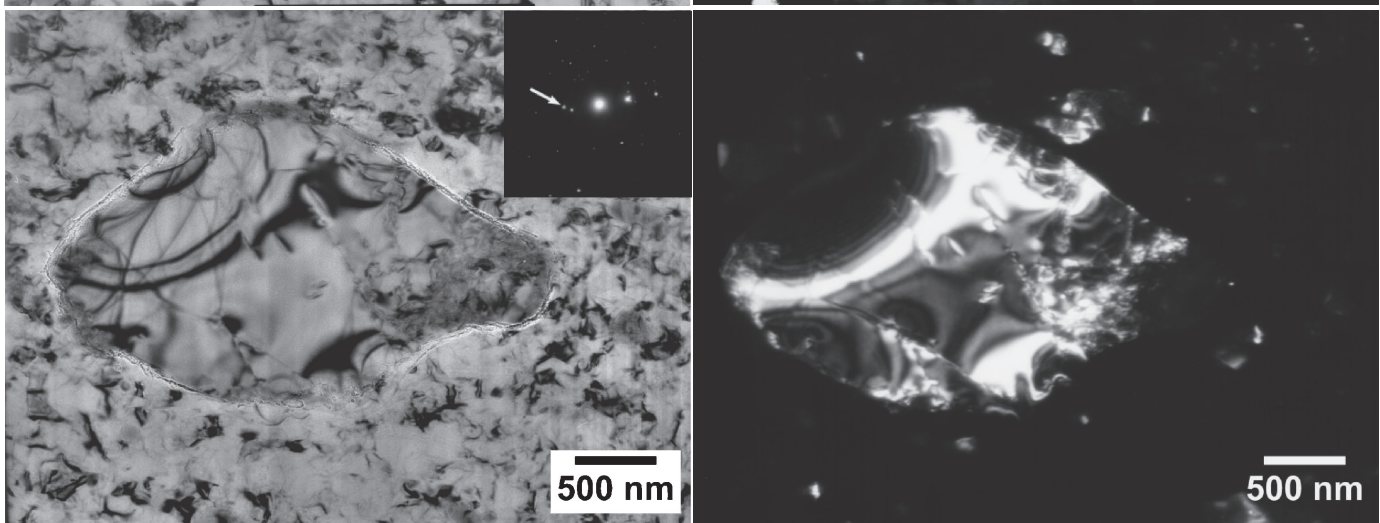

Fig. 7 TEM micrographs of intermetallic particles taken from samples of Al-4\% Fe (a) EXT + ANN + HPT; $N=10$ and (b) EXT + HPT; $N=75$ shown in bright field (left) and dark field (right) obtained from superlattice reflections indicated by arrows in corresponding SAED patterns (as insets in bright field images).

of TEM micrographs as shown in Fig. 8. The grain size of the Al matrix was measured systematically from the dark field images obtained from fundamental Al (111) or (200) reflections as pointed in the inset SAED patterns. It can be observed from the dark field images that the grain size is efficiently refined from the early stages of deformation. After processing for only 1 revolution the average grain size was refined from the as-extruded size of $d \approx 1370 \mathrm{~nm}$ to $d \approx 370 \mathrm{~nm}$ and after $N=5$ to $d \approx 285 \mathrm{~nm}$. The microstructure is then gradually refined at the higher stages of deformation: $d \approx 240 \mathrm{~nm}$ at $N=10, d \approx 175 \mathrm{~nm}$ at $N=20$, $d \approx 170 \mathrm{~nm}$ at $N=50$ and $d \approx 160 \mathrm{~nm}$ at $N=75$ revolutions. These results suggest that the microstructure is saturated at this level of imposed strain. It should be noted that the grain size of the EXT+ANN sample was $2760 \mathrm{~nm}$ but it was reduced to $d \approx 590 \mathrm{~nm}$ at $N=10$ and $d \approx 210 \mathrm{~nm}$ at $N=75$ revolutions. The refinement of the grain size occurs in a similar way as the EXT samples although the grain size is invariably larger.

Figure 9 shows the distribution of grain sizes measured from several micrographs from the sample extracted at the periphery of the disk processed for the EXT sample after 75 revolutions. It is concluded that an ultrafine-grained structure with more than $90 \%$ of the grains with sizes below $d=300 \mathrm{~nm}$ was produced by the HPT process. Another important point to highlight is that the fine intermetallic phase is no longer distinguishable from the images in Fig. 8 although it was possible prior to HPT as shown in Figs. 2(c) and 2(d).
The effect of the microstructural refinement was evaluated in terms of the microhardness measurements. Figure 10 shows Vickers microhardness plotted against the distance from the disk center after processing for higher numbers of revolutions as $N=20,50$ and 75 . The hardness increases with the distance from the disk center which is marked as a vertical dotted line in each plot. This trend is expected since the strain in HPT is a direct function of the distance from the disk center, and it was more pronounced in the EXT + HPT disk processed for $N=20$ revolutions. After processing for $N=50$ and 75 revolutions, the hardness reached a saturated level of $\sim 200 \mathrm{HV}$ which is extended to most of the disk except for the region near the center of the disk. The initial level of hardness prior to HPT was indicated both in the EXT and EXT+ANN samples with a horizontal line in every plot of Fig. 10: note that the initial difference in the hardness is of $\sim 15 \mathrm{HV}$ between the EXT and EXT+ANN samples. It is clear that the degree of strengthening achieved by HPT is quite significant. It appears that the initial difference in the hardness, attributed to their different microstructures, had an effect on the rate of strengthening during the application of HPT. The evolution of the EXT+ANN samples is gradual when compared to the EXT samples. This is due to the fine dispersion of intermetallic particles before HPT, and thus, dislocations are more likely to accumulate and strain hardening occurs more pronouncedly. The EXT+ANN sample processed for $N=75$ is still not fully saturated throughout the whole disk but, in the saturated regions, the hardness reached a level of $\sim 180 \mathrm{HV}$. 


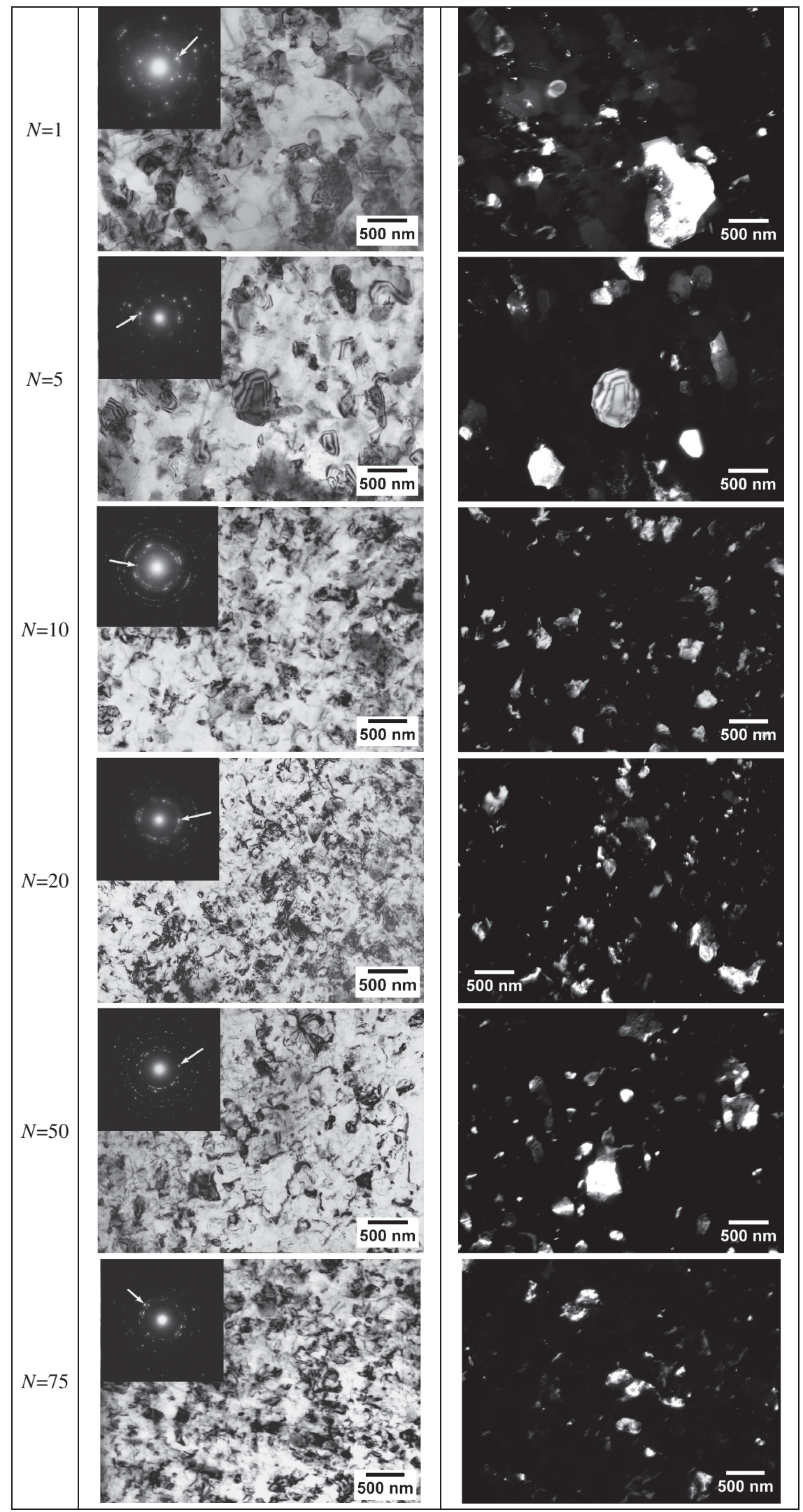

Fig. 8 TEM micrographs showing Al-4\% Fe EXT+HPT microstructure evolution. Dark field images obtained from diffracted beams indicated by arrows in corresponding SAED patterns (as insets in bright field images).

The evolution in microhardness can be further understood if the data are plotted against the equivalent strain [eq. (1)]. Figure 11 shows the corresponding plots for the EXT and $\mathrm{EXT}+\mathrm{ANN}$ disks after processing by HPT. In general it can be said that for both cases data points consistently follow a single line, drawn in both plots to exemplify the behavior of microhardness with the strain induced by torsion. The data in the EXT case show a sharper increase in microhardness as 
described earlier, also with higher local variation, probably due to the initial heterogeneity in the extruded material. As exemplified earlier in the discussion of Figs. 2(c) and 2(d), an initially finer grain structure and intermetallic particles potentiated the strain hardening. The evolution of the EXT+ANN samples, exhibited a similar trend, but gradual if compared to the as-extruded case. Before HPT, the average grain size of the EXT material, $d=1.4 \pm 0.2 \mu \mathrm{m}$, is smaller by a factor of two compared to the EXT+ANN case of $d=2.8 \pm 0.3 \mu \mathrm{m}$. The intermetallic particles in the EXT case, especially the spherical dispersion of eutectic nature,

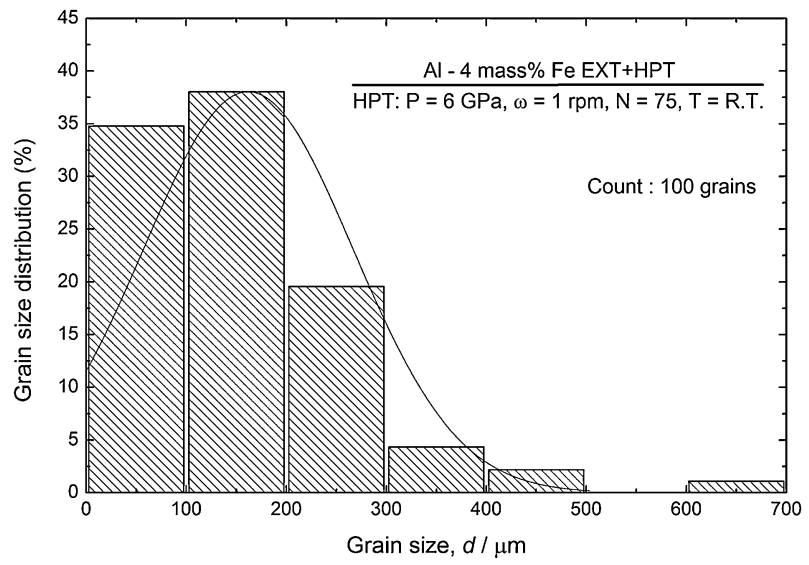

Fig. 9 Distribution of grain size in the EXT+HPT sample processed for $N=75$ revolutions.
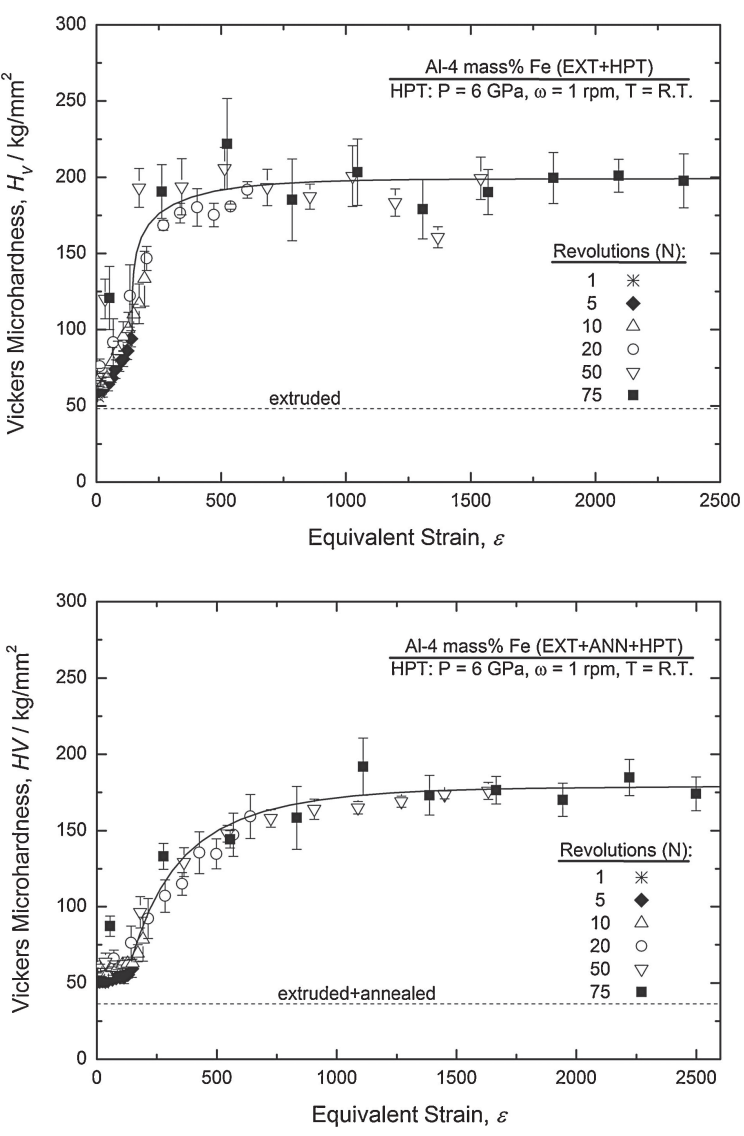

Fig. 11 Vickers microhardness against equivalent strain of EXT+HPT disks (upper image) and EXT+ANN+HPT disks (lower image).
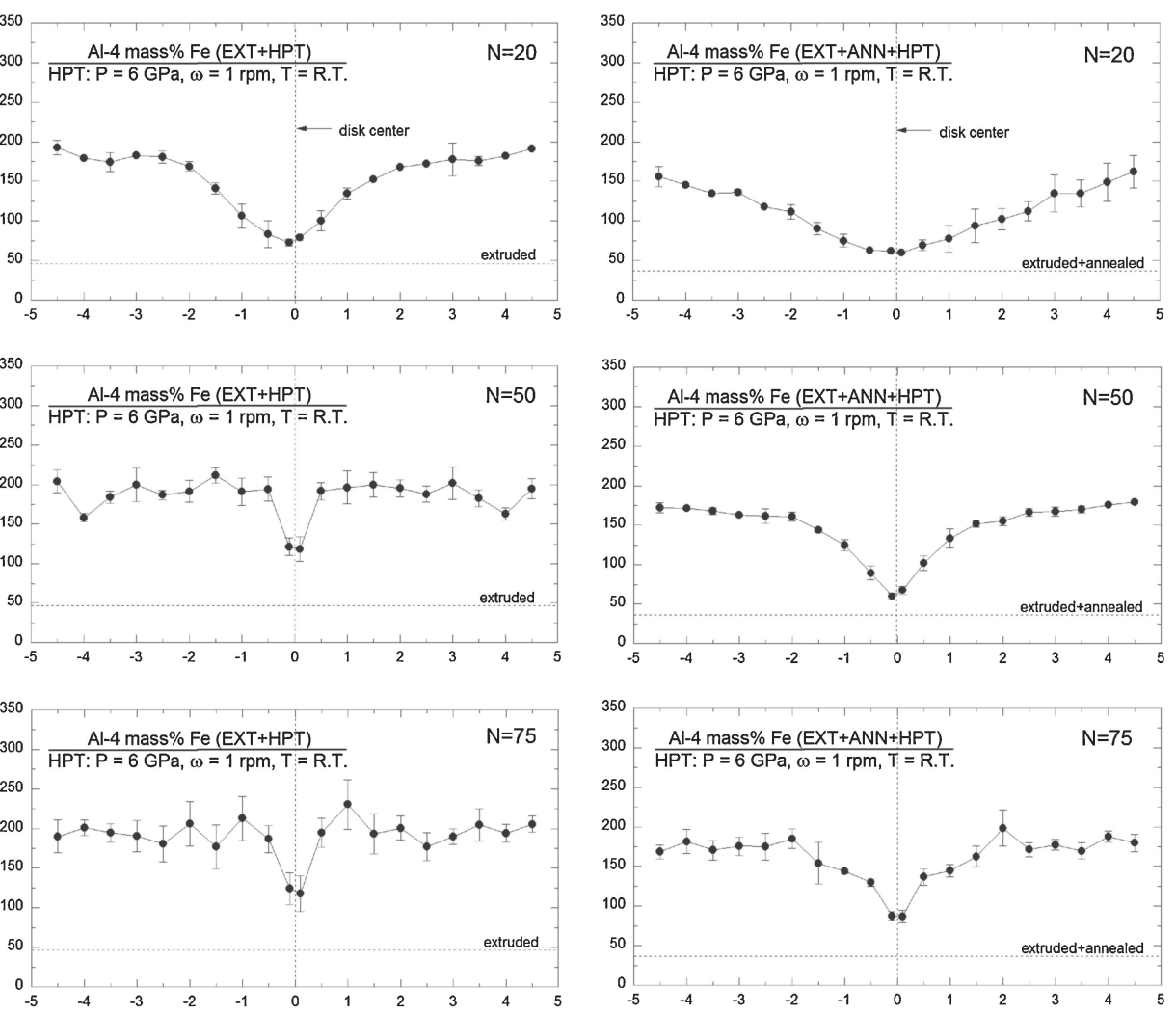

Distance from disk center, $r / \mathrm{mm}$

Fig. 10 Vickers microhardness against distance from disk center of EXT+HPT (left) and EXT+ANN+HPT (right) disks processed for $N=20,50$ and 75 revolutions (as indicated in each graph). 


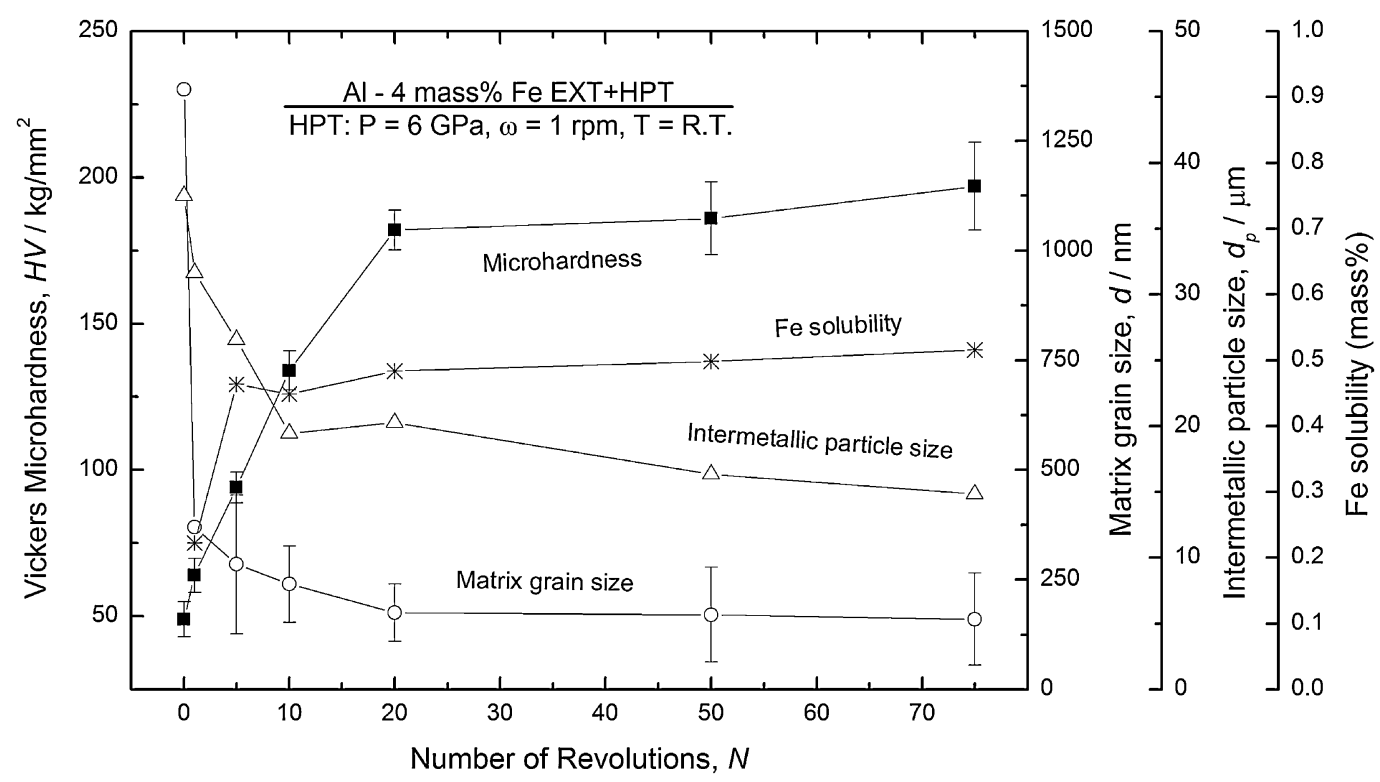

Fig. 12 Vickers microhardness, matrix grain size, intermetallic particle size and Fe solubility against number of revolutions for EXT+HPT disks.

with a size of $d_{\mathrm{p}}=0.18 \pm 0.05 \mu \mathrm{m}$ is also considerably smaller and homogeneous when compared to the EXT+ANN case, with a size of $d_{\mathrm{p}}=0.29 \pm 0.13 \mu \mathrm{m}$.

Figure 12 plots the average values of Vickers microhardness in the periphery of the EXT+HPT disks as a function of the number of revolutions. As described earlier, the grain refinement in the Al matrix as well as the fragmentation and dispersion of the secondary phase play a major role for the significant increase in the strength of this alloy. It is shown that the microstructural refinement and the hardness increase are accelerated in the initial stage of HPT straining and saturated in the later stage. The amount of Fe in solid solution also increased as a result of processing by HPT in a similar manner, sharply during smaller numbers of revolutions and then gradually continues to increase. After $N=75$ revolutions the amount of $\mathrm{Fe}$ in supersaturated solid solution is $\sim 0.5$ mass $\%$.

\section{Summary and Conclusions}

This work examined the evolution of the hardness and microstructures in a bulk $\mathrm{Al}-4$ mass $\% \mathrm{Fe}$ alloy processed by HPT with two different initial microstructural states as extruded and a combination of extruded and annealed. The following conclusions can be extracted from the results presented in this work:

(1) The observation of the microstructure at the initial state showed the presence of a fine intermetallic phase of eutectic nature with a size of $d_{\mathrm{p}} \sim 180 \mathrm{~nm}$ and a coarse secondary phase with a size of $d_{\mathrm{p}} \sim 38 \mu \mathrm{m}$ but with complex morphology of large variation in sizes. The average initial grain size of the Al matrix was $d \approx 1370 \mathrm{~nm}$.

(2) The microstructure appeared to be partially coarsened as a result of the annealing at $773 \mathrm{~K}$ for $1 \mathrm{~h}$, but the presence of $\mathrm{Fe}$ restricted the growth in contrast to pure Al. The intermetallic particles grew with annealing as well.

(3) The Al matrix was refined to an ultrafine-grained microstructure with an average grain size of $d \approx 160 \mathrm{~nm}$ after
$N=75$ revolutions for the extruded samples and that of $d \approx 210 \mathrm{~nm}$ after $N=75$ revolutions for the extruded and annealed samples.

(4) Fragmentation of the coarse intermetallic phase to an average size of $d_{\mathrm{p}} \sim 15 \mu \mathrm{m}$ after $N=75$ revolutions was confirmed by $\mathrm{OM}$ as a result of the intense strain in the extruded and annealed samples.

(5) The refinement of smaller particles and fragments was demonstrated by TEM observations but it was difficult to distinguish the particles from the ultrafine grains achieved in the Al matrix to similar levels.

(6) Microhardness increased significantly after the application of HPT, sharply for the extruded samples from an initial level of $\sim 50 \mathrm{HV}$ to a saturated state of $\sim 200 \mathrm{HV}$ after $N=75$ revolutions, being homogeneously distributed throughout-the disk.

(7) For the annealed samples, microhardness increased gradually from an initial level of $\sim 35 \mathrm{HV}$ to $\sim 180 \mathrm{HV}$ after $N=75$ revolutions, being close to a saturated state and with reduced local variation.

(8) The strengthening of the Al-4\%Fe alloy by HPT processing is well correlated both with the refinement of the intermetallic phases and the ultrafine grain refinement in the $\mathrm{Al}$ matrix. The trend of Fe solubility in the matrix is also consistent with the increase in strength.

(9) A supersaturation of $\mathrm{Fe}$ in the $\mathrm{Al}$ matrix was produced as a result of processing by HPT, reaching a level of $\sim 0.5$ mass $\%$ after $N=75$ revolutions.

\section{Acknowledgements}

This study was carried out as a part of the program in Japan Aluminum Association. One of the authors (JC) thanks the Ministry of Education, Culture, Sports, Science and Technology (MEXT) of Japan for a PhD scholarship. The authors thank Dr. Kaveh Edalati and Mr. Seungwon Lee for their helpful assistance and discussion on this study. This work was supported in part by the Light Metals Educational 
Foundation of Japan, in part by a Grant-in-Aid for Scientific Research from the Ministry of Education, Culture, Sports, Science and Technology of Japan in the Innovative Area "Bulk Nanostructured Metals", and in part by Kyushu University Interdisciplinary Programs in Education and Projects in Research Development (P\&P).

\section{REFERENCES}

1) J. E. Hatch: Aluminum: Properties and Physical Metallurgy, (American Society for Metals, Materials Park, OH, 1984) pp. 25-57.

2) G. E. Totten and D. S. MacKenzie: Handbook of Aluminum Volume I, (Marcel Dekker, Inc., 2003) pp. 81-210.

3) N. A. Belov, A. A. Aksenov and D. G. Eskin: Iron in Aluminum Alloys: Impurity and Alloying Element, (Taylor and Francis, London, 2002) pp. 1-7.

4) U. R. Kattner and B. P. Burton: ASM Handbook Vol. 3: Alloy Phase Diagrams, (ASM International, Materials Park, OH, 1992) p. 44.

5) A. Lendvai: J. Mater. Sci. Lett. 5 (1986) 1219-1220.

6) P. Villars, L. D. Calvert and W. B. Pearson: Pearson's handbook of crystallographic data for intermetallic phases, (American Society for Metals, Materials Park, OH, 1985) pp. 814-817.

7) P. J. Black: Acta Crystallogr. 8 (1955) 175-182.

8) K. Edalati, Y. Ito, K. Suehiro and Z. Horita: Int. J. Mat. Res. (formerly Z. Metallkd.) 100 (2009) 1668-1673.
9) C. Xu, Z. Horita and T. G. Langdon: Mater. Trans. 51 (2010) 2-7.

10) B. B. Straumal, B. Baretzky, A. A. Mazilkin, F. Phillipp, O. A. Kogtenkova, M. N. Volkov and R. Z. Valiev: Acta Mater. 52 (2004) 4469-4478.

11) A. A. Mazilkin, B. B. Straumal, E. Rabkin, B. Baretzky, S. Enders, S. G. Protasova, O. A. Kogtenkova and R. Z. Valiev: Acta Mater. 54 (2006) 3933-3939.

12) Y. Harai, Y. Ito and Z. Horita: Scr. Mater. 58 (2008) 469-472.

13) O. N. Senkov, F. H. Froes, V. V. Stolyarov, R. Z. Valiev and J. Liu: Nanostruct. Mater. 10 (1998) 691-698.

14) O. N. Senkov, F. H. Froes, V. V. Stolyarov, R. Z. Valiev and J. Liu: Scr. Mater. 38 (1998) 1511-1516.

15) V. V. Stolyarov, R. Lapovok, I. G. Brodova and P. F. Thomson: Mater. Sci. Eng. A 357 (2003) 159-167.

16) S. D. Kaloshkin, V. V. Tcherdyntsev, I. A. Tomilin, D. V. Gunderov, V. V. Stolyarov, Y. V. Baldokhin, I. G. Brodova and E. V. Shelekhov: Mater. Trans. 43 (2002) 2031-2038.

17) V. V. Tcherdyntsev, S. D. Kaloshkin, E. A. Afonina, I. A. Tomilin, Y. V. Baldokhin, E. V. Shelekhov, D. V. Gunderov, I. G. Brodova and V. V. Stolyarov: Defect Diffus. Forum 216-217 (2003) 313-322.

18) V. V. Tcherdyntsev, S. D. Kaloshkin, D. V. Gunderov, E. A. Afonina, I. G. Brodova, V. V. Stolyarov, Y. V. Baldokhin, E. V. Shelekhov and I. A. Tomilin: Mater. Sci. Eng. A 375-377 (2004) 888-893.

19) R. Z. Valiev, Y. Estrin, Z. Horita, T. G. Langdon, M. J. Zehetbauer and Y. T. Zhu: JOM 58 (2006) 33-39.

20) H. Jones: Scr. Metall. 17 (1983) 97-100. 